\title{
Innovation of Traditional Clay Sculptures under the Modern Environment
}

\author{
Fangyan Xu
}

Teacher Education Department, Nanchong Vocational and Technical College, China

\begin{abstract}
The rapid development of social economy and fast promotion of modern level have brought some impacts on the development of traditional clay sculptures. In order to make the excellent traditional cultures of Chinese people can get better tradition and development, the survival concept should be fully improved and combine with modern environment to innovate the product design and marketing. Therefore, the development of traditional sculpture should be correctly viewed and commented with more wide vision. Meanwhile, the development of traditional handicraft industry should be integrated with regional overall plan. It can make the traditional clay sculpture get better inheritance and development under the modern environment to make the complete innovation on the basis of guaranteeing the national quality of traditional culture art and fully preserving the art.
\end{abstract}

Keywords: traditional clay sculpture; modern environment; innovation.

\section{传统泥塑在现代环境下的创新性}

\author{
徐芳艳 \\ 四川南充职业技术学院, 四川, 中国
}

摘要: 随着社会经济的飞速发展, 现代化水平的飞速提升, 对于传统泥塑的发展也造成了一 定冲击。想要使得中华民族的优秀传统文化得到更好的传承与发展, 就需要改善其生存观念, 通过与现代环境的有效融合, 对产品的设计、市场的营销等都必须创新。因此, 还需要以更 加广阔的视野正确的看待与评价传统泥塑的发展, 同时要将传统的手工艺产业的发展与地区 的总体规划相结合。在保证传统文化艺术中的民族气质与艺术得到充分保存的基础上, 对其 进行充分的创新, 才够在现代环境中使传统泥塑得到更好的传承与发展。

关键词：传统泥塑；现代环境；创新性。

\section{1. 前言}

泥塑作为一种非常独特的文化现象, 其艺术形式是对于劳动人民日常生产生活的总结与升华, 主要体现了劳动人民的日常生活与独特的民俗文化。在我国泥塑的发展历史最早可最追溯到 新石器时期, 并在汉代成为了重要的艺术形式之一, 一直发展至今。但由于经济水平的飞速 提升, 也给传统泥塑文化的发展带来了新的发展机遇与巨大的挑战。如今, 想要使得传统的 泥塑文化得到更好的发展, 就需要与现代环境进行充分的结合与创新。因此, 本文主要对传 统泥塑在现代环境下的创新性进行研究分析。

\section{2. 传统泥塑的基本概念}

泥塑，俗称 “彩塑”泥塑艺术是中国民间传统的一种古老常见的民间艺术。即用粘土塑制成 各种形象的一种民间手工艺。它以泥土为原料, 以手工捏制成形，或素或彩，以人物、动物 为主。泥塑在民间俗称 “彩塑”、“泥玩”。泥塑发源于宝鸡市风翔县，流行于陕西、天津、 
江苏、河南等地。2006 年 5 月 20 日入选第一批国家级非物质文化遗产名录。而传统泥塑艺 术作为我国独特的民间艺术，在我国民间已经发展了数千年。

传统泥塑作为传统民间玩具的主要组成部分, 其最初是来源于古老的巫术信仰, 是对人们最 原始的崇拜观念的映现。因此，我们在很多的史料典籍中也能够寻找到关于传统泥塑的内容。 比如在孟元老所著的《东京梦华录》中就曾说到 “七月七日, 潘楼街东宋门外瓦子, 州西梁 门外瓦子，北门外，南朱雀门外街及马行街内，皆卖磨喝乐，乃小塑土偶耳”。

在古代, 泥塑主要是人们进行娱乐玩要时使用的物件, 其作为我国民间艺术的主要组成部分, 影响极为深远。传统的泥塑其与人民群众日常的生产生活及风俗礼节间有着极为紧密的联系。 并且其基本都超越了本身所具有的意识形态。目前, 传统的泥塑文化作为中国乡土文化中最 为典型的符号, 特别是在无锡惠州, 天津的 “泥人张”, 四川南充的面泥, 有着极为悠久的 传统泥塑历史，其作为我国非物质文化遗产得到了广泛的传承及发展。

\section{3. 现代环境的实际含义}

我们一般将某一中心事物对于外部世界特征的具体特征成为环境, 其基本都是相对于具体一 个中心事物来说的, 环境也根据其中心事物的的差异呈现出不同的事物, 其是随着中心事物 的变化而发生变化的。通常来说, 环境其实就是对于人类所处的环境的统称, 其又由自然的 地理环境与社会的经济环境以及文化环境所组成。而在 “现代” 的含义内容则较为丰富, 其 中比较多见的含义是 “最近的” 或者是 “直到最近的” , 其所对应的是 “过去的” 意义, 具 体来说就是历史上的最近的一种独特的社会文化的结构形态。

而本文所描述的 “现代环境” ，其实指的就是传统泥塑所在的现代社会的社会经济环境以及 文化环境。

\section{4. 传统泥塑在现代环境下的生存困境}

4.1 样式较为传统保守, 需求量不断降低

传统泥塑作为民间的传统艺术, 长久以来其基本都只能够在比较封闭区域内流传, 很少与外 界环境交流, 虽然其将区域性独特的艺术造型特色保存了下来, 但也使得传统泥塑自身的发 展受到了严重的制约, 有着鲜明的程式化问题存在。另外, 由于其主要利用手工进行制作, 所以其基本都是以家庭为单位的传统作坊式的生产模式, 不仅产品结构较为单一, 且生产数 量有限且需要较长的时间, 很难符合快节奏的市场经济生活需要。因此, 在现代环境下已经 不具备经济价值的实现, 其主要还是精神层面的内涵。并且随着市场经济的快速发展, 人们的 消费方式及生活习惯都发生了极大的改变, 传统泥塑的市场需求量不断降低。

4.2 逐渐流失的传统信仰精神

在传统泥塑的产生及发展的过程中，民间艺人们进行泥塑文化创造的根本动力就是在民间所 具有的强大的信仰精神力量, 民间艺人不仅仅只是为了呈现出艺术作品而进行艺术创造的, 更重要的是体现除了生产生活及精神的实际需求。如：公益广告让泥人张彩塑 “梦娃” 的形 象在全国家喻户晓。但在社会向多元化进行不断发展的背景下, 当前社会的传统信仰精神正 在不断流失, 也导致传统泥塑的发展逐步走向困境。

4.3 市场经营较为混乱, 存在无序竞争的情况

有相关泥塑调查研究结果表明, 当前基本各地的泥塑文化都没有较为明确的标志, 其包装也 比较的不统一, 并且也没有对于作坊名称的标注, 知识在每个具体的泥塑造型后简单的进行 了印章的标记。因此, 若想要使得传统泥塑文化及作品更好的融入现代环境, 就必须要对泥塑 产品进行创新性的设计, 但其存在较大的困难。尤其是随着现代市场竞争的愈发激烈, 给传 统泥塑的发展创新也带来了极大的挑战。但当前传统泥塑所在区域的各大旅游景区中, 都能 看到各种泥塑纪念品。但却不能对其来源进行确定, 这也证明竞争的无序性所造成的市场的 混乱, 在很大程度上也严重影响了传统泥塑的创新发展。 


\section{4 现代玩具对于传统泥塑的冲击}

传统泥塑作为一种传统的玩具, 通常来说只有确保其是处于自然经济环境下的情况下, 其原 始性才能够得到良好的传承。但是, 随着社会及文化环境的不断转型升级, 导致传统泥塑文 化的原始性在现代环境的冲击下逐渐消失，也不再具备最初的实用功能。当前基本没有人再 利用泥塑对历史事件及英雄人物进行祭祀, 对于现代人们而言, 其成为了带有地方特色与吉 祥寓意的传统手工艺品。但是现代的玩具又有着漂亮的造型、独特的艺术风格与较强的互动 性和操作性, 这无形中也对传统泥塑造成了极大的冲击, 甚至影响着其身份与内涵的变化。

\section{5. 传统泥塑在现代环境中的创新研究}

\section{1 改善传统单一的传承及生产模式}

长久以来, 我国传统泥塑的主要生产形式属于家庭手工业, 其主要的生产场所是家庭, 主要 的产生者是家庭劳动力, 传承者就是家庭成员, 其生产与销售都具有较强的自主性。若想要 传统泥塑得到现代化的融合与发展, 就要能够充分的改善其传承方式与生产模式。当前这种 比较封闭隔离的制作模式极大程度的阻碍了传统泥塑的创新与发展, 因此也使得具有较强文 化艺术展示性质的表演制作逐渐兴起。可以在一些公开大型的活动中，展示一些代表性的传 统泥塑作品及制作过程的展示, 就可以充分的提升人民群众的兴趣, 使其更加了解传统文化。 5.2 改变传统的销售方式，提升品牌的知名度

随着经济全球化的发展，传统的民间泥塑仍旧极为缺乏市场认知度与知名度。所以，想要使 得传统泥塑得到更好的发展, 就要加大关于传统泥塑的宣传力度, 通过对于多种方式树立品 牌, 比如: 天津的 “泥人张” ，对市场进行开拓。因此，当前最重要的是要能够将当前的所 应用的泥塑产品的外形与营销方式进行转变，从而满足市场及消费者的实际需求。受到现代 社会快速发展的冲击, 当前年轻人对于时尚新潮的事物有着极大的追求, 因此泥塑的造型也 可以逐渐向此方面发展, 仍旧可以应用比较传统的捏制手法, 但可以尝试对其造型进行创新。 另外，还应该适当的创新其营销手段。当前传统泥塑主要的营销手段是在庙会或市场上进行 的摊位式销售, 其存在较大的流动性, 且其稳定性不强, 受众人群较少。而随着网络技术的 普及, 当前基本家家户户利用网络了解外界信息。所以就可以让当地的手工艺人充分的利用 网络这种良好的销售手段, 通过网络加大宣传力度, 使更多的人了解到泥塑这一传统文化艺 术形式。同时, 还应该多花心思在泥塑造型的档次及艺术性, 使其具有较强的市场竞争力, 从 而在现代环境下实现传统泥塑的创新发展。

5.3 加大对于文化创意人才的引进与培养

想要使得传统泥塑文化产业得到更好的发展, 还需要对文化创意性人才进行创新与培养。我 国当前教育事业发展迅速且有着极为丰富的教育资源，各个高等院校都有艺术设计专业课的 开设，设立了非物质文化遗产大师工作室，并且很多高校都积累了丰富的经验。因此，对于 高校来说, 要重视对于创意设计人才的重点培养。特别是对于泥塑传承人来说, 其地方高校 更是要加大对于本土的传统文化创意设计人才及产业策划管理人才的重点培养与引进。另外, 在对其进行培养的过程中, 首先就要明确方向, 对其未来的发展方向进行确定, 从而对学生 进行针对性的培养。此外, 作为创新性人才, 就要足够的重视其设计能力与创意能力, 使其 在今后的生活工作过程中能够为传统泥塑的创新贡献自己的力量。

\section{4 传统泥塑要能和现代环境充分的融合}

想要使我国的传统泥塑在现代社会环境中得到更好的发展, 就必须要对其进行充分的创新。 能够在传统泥塑本身所具有的文化底蕴内涵基础上与现代化的设计元素及理念进行充分的融 合, 之后在对泥塑作品进行创新设计。也就是说, 要能够转变传统泥塑的文化形式, 从而满 足现代人的实际需求，也可以将现代生活题材作为其设计来源，从而使得社会对于我国的传 统手工艺品及地区的民俗文化进行充分的了解。传统泥塑的创新性发展, 还要能够和其所具 有的艺术特色、功能特点以及审美情趣等进行充分的结合, 通过不断的创新性改良与设计, 和地方政策的支持，促进其得到更好的发展。另外，由于河南传统的泥塑文化有着较强的人 
文性与极为丰富的历史内涵, 因此在进行现代设计的过程中, 还需要充分的结合传统文化及 现代流行，使得传统的泥塑文化迸发出新的活力，得到创新性的传承与发展。

5.5 灵活应用周边产品

周边产品实际上就是文化附属的产品, 其可以是软周边, 也可以是硬周边。硬周边产品就是 由具体的造型及形象所设计的产品, 其具有较强的实用价值, 比如一些文具、日常生活用品 等等。而软周边则指的是只具有观赏价值的一些艺术品, 比如玩偶与模型等等。通过对于周 边产品的灵活应用, 传统的泥塑文化就能够更加深入的渗透到普通群众的日常生活中, 实现 对于传统泥塑的创新性传承。

\section{6. 结论}

综上所述，由于传统泥塑的式样仍旧是传统模式，存在较强的区域性与单一性，导致其受到 了现代环境的剧烈冲击, 使得当前传统泥塑文化的发展受到了严重的制约。因此, 想要更好 的对泥塑这种传统的艺术文化形式进行传承与发展, 就要对其生存观念进行有效的改善, 与 现代环境背景进行充分的融合, 通过现代化的理念与手段对泥塑进行创新性的设计, 更重要 的是还要对现代化的市场运作手段进行充分的应用, 使得泥塑文化得到更多人的知晓和喜爱, 通过一定的政策扶持, 引进传统文化进校园, 与旅游产业相结合, 实现对于大量现代化泥塑 人才的培养。最终，使得传统泥塑得到创新性的传承与发展。

\section{References}

[1]. Xin Shi. The Analysis with the Clay Sculpture Culture Development in Central Plains Region[J]. Prose Parterre (New Chinese leaflet),2017(11):88.

[2]. Yue Zhang. Innovative Research of Chinese Traditional Handicraft in Cultural Creative Product Design[D]. Beijing Construction University,2017.

[3]. Peipei Ma. Current Status and Countermeasures Research of Henan Clay Sculpture Culture Creative Design[J]. Journal of Qiqihar University (Philosophy and social science), 2013(06):51-52.

[4]. Ming Shang. Innovative Research of Henan Traditional Clay Sculpture under the Modern Environment[D]. Southwest Jiaotong university,2011.

[5]. Weiwei Yu. Innovative Inheritance of Intangible cultural heritage[D]. Shandong College of Arts,2011. 